\title{
Shame-based messaging and obesity campaigns: More harm than good?
}

\section{Sarah Frood \& Lee M. Johnston}

\section{Simon Fraser University}

The profile of childhood obesity as a public health issue has increased dramatically in recent years, to the extent that the World Health Organization has identified it as one of the most serious public health challenges of the 21st century. ${ }^{1}$ While a myriad of questions persist over what constitutes best practice in obesity prevention and management, many argue that any action taken to address the issue should evaluate the potential impact on weight bias and stigma. This need was driven home recently by a controversial media campaign in Atlanta, Georgia, produced by the notfor-profit organization Children's Healthcare of Atlanta. The 'Strong 4 Life' campaign features somber, overweight child actors in print ads and commercials stating messages such as "Big Bones Didn't Make Me this Way, Big Meals Did" and "It's Hard to be a Little Girl When You're Not". The campaign constitutes a shock and awe advance in the "war" on obesity that is taking place in North America.

The Strong 4 Life campaign is defending their approach by suggesting that this "tough love" strategy will motivate parents and children to change their lifestyles. ${ }^{3}$ Parents are directed to a campaign website that provides suggestions on how to discuss child body weight with a physician. Tips are also offered on changing behaviours associated with obesity. While there may be benefits in drawing parents into the site with a sensationalistic social marketing campaign, a message like "Stocky, Chubby, Chunky are Still Fat" suggests that negative responses towards obese individuals, children or otherwise, are appropriate. Compounding the ethical issues surrounding this approach is the fact that current research does not support the effectiveness of shame-based messaging in addressing weight and obesity; rather, these campaigns may do more harm than good by perpetuating stigma.

The harmful side effects of the stigmatization and shame associated with being obese are well documented, and extend to non-obese individuals who become preoccupied with body image. ${ }^{4}$ An individual's experience with weight stigma can have a negative impact on weight loss, increase unhealthy weight control behaviours, and lead to depression, low self-esteem, and poor body image. ${ }^{4}$ Stigmatization of obese individuals not only poses risks to psychological and physical health, but can also interfere with the implementation of effective obesity prevention measures. ${ }^{5}$ In spite of this, the use of shame as a motivational tactic persists with regards to obesity. This might be due to the success of other similar public health media campaigns. For example, anti-tobacco campaigns that have featured negative emotional appeals have proven to be highly effective in changing behaviour. ${ }^{6}$ However, tobacco is a high-risk activity for which the ideal solution is complete cessation. The task of addressing obesity through behavioural change is going to require a more nuanced approach that deals with the complexity it poses.

Many of our public health policies and interventions have traditionally focused on the individual by promoting an "eat less, move more" paradigm to address problems associated with body weight.7 There is a growing trend, however, towards accepting obesity as a complex problem that is influenced by factors from the environmental, social and biological fields. Foresight, a UK policy group, has created an evidence-based model of obesity that highlights its complexity by clustering over 100 variables into seven sub-systems: physical activity environment, physiology, individual physical activity, social psychology, individual psychology, food consumption and food production. ${ }^{8}$ If we begin to understand obesity as a system that is influenced by all of these factors and the relationships between them, then it is clear that addressing only individual behaviour will not create a significant impact on the system as a whole. Complex systems science suggests that there is no single solution to obesity, but that multiple interventions and strategies should be implemented with cooperation 
and collaboration between many different sectors. ${ }^{9}$ Part of the solution could involve reframing the focus of obesity interventions from obese individuals to a focus on health and wellness for all individuals in a population. ${ }^{10}$

Well-intentioned public health practitioners are eagerly seeking avenues to lessen the physical and psychosocial burdens suffered by many obese and overweight individuals. However, campaigns like Strong 4 Life present a potentially dangerous approach that could compound these health concerns. Singling out children for their weight in a mass public health appeal as a means of galvanizing parents may contribute to a cycle of shaming and stigma for the children themselves, while also perpetuating weight bias throughout society. Furthermore, decontextualizing individuals from the complex obesogenic environment in which they operate perpetuates a simplistic "eat less and move more" paradigm without addressing the social determinants that may influence decisions regarding food and exercise. Public health practitioners should therefore carefully weigh the perceived benefits against the potential risks associated with these types of interventions.

\section{Acknowledgments}

The authors would like to thank Dr. Diane Finegood, Dr. Carrie Matteson and the Chronic Disease Systems Modeling Lab at Simon Fraser University for their support.

\section{References}

1. World Health Organization. Childhood overweight and obesity [Internet]. 2012 [cited 2012 Feb 5]. Available from: http://www.who.int/ dietphysicalactivity/childhood/en/

2. Children's Healthcare of Atlanta. Strong4Life Addresses Growing Number of Children Who Likely Will Become Overweight or Obese Adults [Internet]. February 16, 2012 [cited 2012 Mar 5]. Available from: http:// www. prnewswire.com/news-releases/strong4life-addresses-growingnumber-of-children-who-likely-will-become-overweight-or-obeseadults-139469903.html

3. Puhl RM, Brownell KD. Fight obesity, not the people. The Atlanta JournalConstitution 2012 January 12 [cited 2012 Mar 5]. Available from: http:// www.ajc.com/opinion/fight-obesity-not-the-1300983.html

4. Puhl RM, Heuer CA. The stigma of obesity: a review and update. Obesity 2009;17(5):941-964

5. Puhl RM, Heuer CA. Obesity stigma: important considerations for public health. Am J Public Health 2010 Jun;100(6):1019-1028.

6. Siegel M. Antismoking advertising: figuring out what works. J Health Commun 2002 Mar-Apr;7(2):157-162.

7. Alvaro C, Jackson LA, Kirk S, McHugh TL, Hughes J, Chircop A, et al. Moving Canadian governmental policies beyond a focus on individual lifestyle: some insights from complexity and critical theories. Health Promot Internation 2011;26(1):91-99.

8. Vandenbroeck P, Goossens J, Clemens M. Foresight tackling obesities: Future choices-Building the obesity system map [Internet]. Government Office for Science, UK Government's Foresight Programme, 2007. Available from: http://www.bis.gov.uk/assets/foresight/docs/obesity/12.pdf

9. Leischow SJ, Best A, Trochim WM, Clark PI, Gallagher RS, Marcus SE, et al. Systems thinking to improve the public's health. Am J Prev Med 2008;35(2):S196-203.

10. Pagnini D, King L, Booth S, Wilkenfeld R, Booth $\mathrm{M}$. The weight of opinion on childhood obesity: recognizing complexity and supporting collaborative action. Int J Pediatr Obes 2009;4(4):233-241.

\section{Sarah Frood}

Sarah Frood is a second year MSc student in the Faculty of Biomedical Physiology and Kinesiology at Simon Fraser University. Her research interests include obesity, weight bias and the use of complex systems approaches in public health.

\section{Lee M. Johnston}

Lee Johnston is currently pursuing a PhD in the Faculty of Health Sciences at Simon Fraser University. Her research interests include health promotion policy and planning, complex systems applications in public health, and health communication. 